\title{
Relative intakes of tar, nicotine, and carbon monoxide from cigarettes of different yields
}

\author{
NICHOLAS J WALD, JILLIAN BOREHAM, ALAN BAILEY \\ From the Imperial Cancer Research Fund Cancer Epidemiology and Clinical Trials Unit, Radcliffe Infirmary, \\ Oxford, and BUPA Medical Research, London
}

ABSTRACT The relative intakes of tar, nicotine, and carbon monoxide were estimated in 2455 cigarette smokers, who freely smoked their usual brands of cigarette. The estimates were derived by using an objective index of inhaling based on the measurement of carboxyhaemoglobin divided by the carbon monoxide yield of the cigarettes smoked, after background and carry over carboxyhaemoglobin effects had been allowed for. Separate analyses were performed according to the yield and type (plain, filter, etc) of cigarette smoked. The analyses based on yield indicated that the extent of inhaling was adjusted sufficiently to achieve similar intakes of nicotine/carbon monoxide regardless of the nicotine/carbon monoxide yield. It was not, however, sufficiently increased to achieve a similar intake of tar as the tar yield of the cigarette decreased. The analyses based on type of cigarette indicated that the extent of inhaling was adjusted to achieve similar intakes of tar and nicotine regardless of the type of cigarette smoked, but that this led to a greater intake of carbon monoxide among filter cigarette smokers than that among smokers of plain cigarettes - more so than would have been expected from their relative carbon monoxide yields. Two conclusions arise from these results. Firstly, any harmful effects of nicotine/carbon monoxide are unlikely to be materially reduced by smoking cigarettes with lower yields of nicotine/ carbon monoxide, but the harmful effects of tar are likely to be reduced by smoking cigarettes with lower tar yields. These predictions appear to be borne out by epidemiological observations. Secondly, any harmful effects of carbon monoxide on the cardiovascular system will be greater in smokers of modern filter cigarettes than in smokers of modern plain cigarettes, provided that these two groups of smokers are otherwise similar with respect to risk of cardiovascular disease.

In an earlier paper we described an objective index of inhaled cigarette smoke based on carboxyhaemoglobin concentration and the carbon monoxide yield of the cigarettes smoked.' Smokers of ventilated filter cigarettes were found to inhale $82 \%$ more than smokers of plain cigarettes and those who smoked unventilated filter cigarettes $36 \%$ more than smokers of plain cigarettes (ventilated cigarettes have perforations in the filter admitting air that dilutes the mainstream smoke). These differences encouraged us to investigate the matter further and estimate the relative intakes of tar, nicotine, and carbon monoxide from cigarettes of different yields.

Address for reprint requests: Professor NJ Wald, Department of Environmental and Preventive Medicine, Medical College of St Bartholomew's Hospital, London EC1M 6BQ.

Accepted 19 December 1983
We did this in a preliminary way in our previous paper in respect of tar and nicotine intakes according to type of cigarette. Here we have extended the observations to include estimates of carbon monoxide intake and have in addition estimated the relative intakes of tar, nicotine, and carbon monoxide according to the yields of the cigarettes and regardless of cigarette type.

\section{Methods}

The study population consisted of men aged 35-64 years who attended the BUPA Medical Centre in London for a comprehensive health screening examination and has been described previously. ${ }^{1}$ The men were asked about their medical history and their usual and recent smoking habits. All information was collected after arrival at the centre, and the 
men were not forewarned about the survey of smoking habits. The time when each cigarette, cigar, or pipe had been smoked that day was recorded, together with the manufacturer's brand. Each man provided a sample of venous blood and the carboxyhaemoglobin saturation was measured as previously described. ${ }^{2}$ The within assay standard deviation of the method was $0.05 \%$ carboxyhaemoglobin. The tar and nicotine yields of the cigarettes were obtained from tables published by the Health Departments of the United Kingdom, and carbon monoxide yields were obtained from the Tobacco Advisory Council. All the yields were obtained under the same experimental conditions. Estimates of relative intakes of tar, nicotine and carbon monoxide were derived by multiplying the average inhaling index in a particular group by the average yields from cigarettes smoked by that group.

Our statistical analyses related to men seen from early 1975 to the end of 1979 who usually smoked only manufactured cigarettes. As before, men who smoked brands of cigarettes for which carbon monoxide yields were not available from the Tobacco Advisory Council were excluded; this applied to less than $5 \%$ of men in our study population. The analysis was restricted to the 2455 men who had smoked 1-16 cigarettes before the blood test on the day they were seen at the medical centre, and from whom blood was taken between 13.00 and 16.00 hours. On the basis of detailed information about recent smoking habits and the carboxyhaemoglobin estimation, each person's carboxyhaemoglobin inhaling index was estimated and this was standardised for the number of cigarettes smoked before the test when different smoking groups were compared in our statistical analyses. The derivation of the carboxyhaemoglobin inhaling index is given in the appendix.

\section{Results}

Table 1 shows the estimated relative intakes of tar, nicotine, and carbon monoxide according to the tar, nicotine, and carbon monoxide yields of the cigarettes smoked. The relative intake of all three smoke constituents was greater from the low yield cigarettes than would have been expected from the cigarette yields, confirming the phenomenon of compensatory smoking previously demonstrated. Indeed, the intake of nicotine and carbon monoxide remained relatively constant regardless of the cigarette yield. Only the intake of tar declined with declining tar yield.

Table 2 shows the relative cigarette yield and relative intake of tar, nicotine, and carbon monoxide according to type of cigarette (plain, unventilated filter, or ventilated filter).' Our results relating to tar and nicotine are similar to those described before, although the extent of compensation in this extended series is somewhat greater than was observed before. The carbon monoxide intake in smokers of filter cigarettes was about $60 \%$ higher than in smokers of plain cigarettes, but the intake of tar and nicotine was slightly less.

\section{Discussion}

Our present findings confirm the phenomenon of compensatory smoking and indicate that this may be

Table 1 Inhaling index and estimated relative intake of tar, nicotine and carbon monoxide according to quintile of tar, nicotine, and carbon monoxide yield of cigarette

\begin{tabular}{|c|c|c|c|c|}
\hline \multicolumn{2}{|l|}{ Yield } & \multirow[t]{2}{*}{ No of men } & \multirow{2}{*}{$\begin{array}{l}\text { Standardised inhaling } \\
\text { index* }(\mathrm{COHb} \% \mathrm{mg} \mathrm{CO})\end{array}$} & \multirow{2}{*}{$\begin{array}{l}\text { Estimated relative intake } \\
\text { (average yield } \times \text { inhaling } \\
\text { index) }\end{array}$} \\
\hline Quintile & Limits (mg) & & & \\
\hline $\begin{array}{l}\text { TAR } \\
\text { 1st } \\
\text { 2nd } \\
\text { 3rd } \\
\text { 4th } \\
\text { 5th }\end{array}$ & $\begin{array}{l}1- \\
10- \\
18- \\
19- \\
20-36\end{array}$ & $\begin{array}{l}511 \\
544 \\
543 \\
583 \\
274\end{array}$ & $\begin{array}{l}0.30 \\
0.21 \\
0 \cdot 18 \\
0 \cdot 19 \\
0 \cdot 16\end{array}$ & $\begin{array}{l}2 \cdot 62 \\
3 \cdot 21 \\
3 \cdot 33 \\
3 \cdot 54 \\
4 \cdot 59\end{array}$ \\
\hline $\begin{array}{l}\text { NICOTIN } \\
\text { 1st } \\
\text { 2nd } \\
\text { 3rd } \\
\text { 4th } \\
\text { 5th }\end{array}$ & $\begin{array}{l}0.3- \\
1 \cdot 0- \\
1 \cdot 3- \\
1 \cdot 4- \\
1 \cdot 5-3.6\end{array}$ & $\begin{array}{l}551 \\
448 \\
405 \\
418 \\
633\end{array}$ & $\begin{array}{l}0.30 \\
0.21 \\
0.19 \\
0.19 \\
0.17\end{array}$ & $\begin{array}{l}0.24 \\
0.24 \\
0.25 \\
0.27 \\
0.28\end{array}$ \\
\hline $\begin{array}{l}\text { CARBON } \\
\text { 1st } \\
\text { 2nd } \\
\text { 3rd } \\
\text { 4th } \\
\text { 5th }\end{array}$ & $\begin{array}{l}0 \cdot 8- \\
12 \cdot 8 \\
17 \cdot 0- \\
18 \cdot 0- \\
20 \cdot 0-28 \cdot 1\end{array}$ & $\begin{array}{l}473 \\
553 \\
431 \\
638 \\
360\end{array}$ & $\begin{array}{l}0.30 \\
0.21 \\
0.20 \\
0.18 \\
0.16\end{array}$ & $\begin{array}{l}3.50 \\
3.08 \\
3.45 \\
3.49 \\
3.59\end{array}$ \\
\hline
\end{tabular}

*See appendix; standardised for number of cigarettes smoked before the test. $\mathrm{COHb}-$ carboxyhaemoglobin; $\mathrm{CO}-$ carbon monoxide. 
Table 2 Relative cigarette yield and estimated relative intakes of tar, nicotine and carbon monoxide by cigarette type

\begin{tabular}{|c|c|c|c|c|c|c|c|}
\hline \multirow[t]{2}{*}{ Type of cigarette } & \multirow[t]{2}{*}{ No of Men } & \multicolumn{2}{|l|}{ Tar } & \multicolumn{2}{|l|}{ Nicotine } & \multicolumn{2}{|c|}{ Carbon monoxide } \\
\hline & & Relative yield & Relative intake & Relative yield & Relative intake & Relative yield & Relative intake \\
\hline $\begin{array}{l}\text { Plain } \\
\text { Unventilated Filter } \\
\text { Ventilated Filter }\end{array}$ & $\begin{array}{r}185 \\
1666 \\
604\end{array}$ & $\begin{array}{r}100 \\
72 \\
39\end{array}$ & $\begin{array}{l}100 \\
98(5) \\
80(5)\end{array}$ & $\begin{array}{r}100 \\
68 \\
47\end{array}$ & $\begin{array}{r}100 \\
92(4) \\
97(7)\end{array}$ & $\begin{array}{r}100 \\
119 \\
79\end{array}$ & $\begin{array}{l}100 \\
162(8) \\
163(12)\end{array}$ \\
\hline
\end{tabular}

Standard errors are shown in brackets.

greater than has hitherto been appreciated. The results also show that the estimated relative intakes of tar, nicotine, and carbon monoxide do not vary greatly with the yield of the cigarette. Only the relative intake of tar declined with declining tar yields.

The data also demonstrate an important point in connection with the relative intake of carbon monoxide. When our data are analysed according to the yield of the cigarette the relative intake of carbon monoxide remains fairly constant, but when analysed according to the type of cigarette the relative intake of carbon monoxide is about $60 \%$ higher in smokers of filter cigarettes than in smokers of plain cigarettes. This arises largely because, apart from some ventilated cigarettes, filter cigarettes tend to have higher carbon monoxide yields than plain cigarettes. In addition, the smoke from such cigarettes is also inhaled more. This finding does not emerge when the data are analysed according to yield because plain cigarettes during the period of the study represented a very small proportion of the cigarettes smoked.

There are two medical and scientific implications which arise from our results. Firstly, if carbon monoxide or nicotine, or some other constituent of tobacco smoke which is correlated with the yield of these substances, is the cause of the excess risk of heart disease among smokers, smokers of relatively low yield cigarettes would be expected to have about the same excess risk of heart disease as people smoking higher yielding cigarettes. In contrast, the risk of a disease such as lung cancer, which is related to the tar yield of a cigarette, is likely to be lower in smokers of low tar than of high tar cigarettes.

These predictions explain the epidemiological observations on the risk of heart disease and lung cancer in relation to yield and type of cigarette reasonably well. With regard to heart disease, there is a notable recent paper on the risk of myocardial infarction in relation to the nicotine and carbon monoxide yields of cigarettes. The paper showed that there was no significant association between yields of either of these two substances and the risk of disease. ${ }^{3}$ It is apparent from our findings that this result cannot be taken to exclude the possibility that either nicotine or carbon monoxide may be a cause of myocardial infarction. The result can readily be explained by the fact that in that study smokers of low tar and low nicotine cigarettes compensated for the lower yields by greater inhaling. Other epidemiological studies have shown either no decrease in risk of heart disease ${ }^{45}$ with decreasing yields or only a modest decrease. ${ }^{6}$

So far as lung cancer is concerned, several epidemiological studies have shown that the risk is lower in smokers of low tar cigarettes than in smokers of high tar cigarettes, ${ }^{4-12}$ and only one did not. ${ }^{13}$ On the basis of the estimated intake of tar the reduction in risk of lung cancer would not be as much as expected from the relative cigarette yields. It is quite plausible, however, that the increase in inhaling results in a tendency for tar to be inhaled beyond the target site, the main bronchi ${ }^{14}$; and this in itself may contribute to the reduction in risk of lung cancer associated with smoking low tar cigarettes.

The second implication from our results is that the difference in relative tar and nicotine intakes among smokers of plain and filter cigarettes can be exploited epidemiologically to investigate whether carbon monoxide is a possible cause of coronary heart disease. If carbon monoxide is the principal agent in tobacco smoke responsible for cardiovascular disease the risk of heart disease among smokers of filter cigarettes would be expected to be higher than among smokers of plain cigarettes if the smokers are otherwise similar in respect of factors associated with the risk of heart disease. This is unlikely to be the case, since the sections of the community switching to filter cigarettes first are likely to have been those making other changes in their life style, particularly diet, that may have reduced their risk of heart disease. But it will tend to mask rather than introduce an effect. If therefore smokers of filter cigarettes are indeed found to have a higher risk of heart disease than similar groups of plain cigarette smokers this will provide useful epidemiological evidence for the hypothesis that carbon monoxide is a cause of cardiovascular disease.

An objection to using only one component of tobacco smoke, such as carbon monoxide, as an index of the relative intake of other smoke components, such as tar and nicotine, is that it assumes that all the components are inhaled in roughly the same proportion. That this assumption is not completely 
invalid is suggested by the work of Stepney, ${ }^{15}$ which shows that various measures of smoke intake such as nicotine and cotinine excretion in urine, the nicotine retained in the cigarette butt, and the rise in "expired air carbon monoxide over smoking" levels yield similar results during a cigarette switching experiment. ${ }^{15}$ It has also been shown that carboxyhaemoglobin concentrations are closely associated with plasma nicotine concentrations in subjects who smoke cigarettes using different dilution filters. ${ }^{16}$ Benowitz and his colleagues have recently published results similar to our own but with serum, nicotine, and cotinine values instead of carboxyhaemoglobin concentrations. ${ }^{17}$ Their results suggested that smokers of low nicotine cigarettes do not consume less nicotine.

Our results relate to cigarettes smoked in Britain from 1975 to 1979 , and since the design and yields of cigarettes have changed over the last few decades it cannot be assumed that they apply to cigarettes manufactured at different times. This point is particularly relevant when predicting the risk of specific diseases in relation to the type and yield of cigarettes made at different times.

We thank the Medical Research Council for part of our financial support and the Tobacco Advisory Council for providing the carbon monoxide yields of the different brands of cigarette.

\section{Appendix: Derivation of carboxyhaemoglobin inhaling index ${ }^{1}$}

Carboxyhaemoglobin concentrations include a contribution from the carboxyhaemoglobin carryover from the previous day's smoking and the background carboxyhaemoglobin from endogenous and atmospheric carbon monoxide. This contribution was taken as the carboxyhaemoglobin level among men who did not smoke on the day of the test but who had smoked a similar number of cigarettes during the previous evening. The measured carboxyhaemoglobin minus this contribution can be regarded as the "excess" carboxyhaemoglobin.

A quantitative index of inhaling by an individual smoker, which takes account of both the background and the carryover carboxyhaemoglobin as well as the carbon monoxide yield of the particular cigarette smoked, is given by the excess carboxyhaemoglobin concentration divided by the carbon monoxide yield of the cigarette. Since this index depends on the number of cigarettes smoked before the carboxyhaemoglobin test, the mean carboxyhaemoglobin inhaling index for each group of smokers considered in this paper was indirectly standardised for the number of cigarettes smoked, and we call this the standardised carboxyhaemoglobin inhaling index.

\section{References}

${ }^{1}$ Wald NJ, Idle M, Boreham J, Bailey A. Inhaling habits among smokers of different types of cigarette. Thorax 1980;35:925-8.

${ }^{2}$ Wald N, Idle M, Bailey A. Carboxyhaemoglobin levels and inhaling habits in cigarette smokers. Thorax 1978;38:201-6.

${ }^{3}$ Kaufman DW, Helmrich SP, Rosenberg L, Miettinen OS. Shapiro'S. Nicotine and carbon monoxide content of cigarette smoke and the risk of myocardial infarction in young men. $N$ Engl $J$ Med 1983;308:409-13.

${ }^{4}$ Hawthorne VM, Fry JS. Smoking and health; cardiorespiratory disease, mortality and smoking behaviour in West Central Scotland. Journal of Epidemiology and Community Health 1978;32:260-6.

5 Castelli WP, Garrison RJ, Dawber TR, McNamara PM, Feinleib M, Kannell WB. The filter cigarette and coronary heart disease: the Framingham Study. Lancet 1981;ii:109-13.

'Hammond EC, Garfinkel L, Seidman H, Lew EA. "Tar' and nicotine content of cigarette smoke in relation to death rates. Environ Res 1976;12:263-74.

7 Bross IDJ, Gibson R. Risk of lung cancer in smokers who switch to filter cigarettes. Am J Publ Health 1968;58:1396-403.

${ }^{8}$ Wynder EL, Mabuchi K, Beattie EJ. The epidemiology of lung cancer. Recent trends. JAMA 1970;213: 2221-8.

9 Wynder EL, Stellman SD. The impact of long-term filter cigarette usage in lung and larynx cancer risk: a casecontrol study. J Natl Cancer Inst 1979;62:471-7.

${ }^{10}$ Rimington J. The effect of filters on the incidence of lung cancer in cigarette smokers. Environ Res 1981; 24:162-6.

" Higenbottam T, Shipley MJ, Rose G. Cigarettes, lung cancer, and coronary heart disease: the effects of inhalation and tar yield. Journal of Epidemiology and Community Health 1982;36:113-7.

12 Vatuc C, Kunze M. Lung cancer risk in women in relation to tar yields of cigarettes. Prev Med 1982; 11:713-6.

${ }^{13}$ Reid DD. Background and design. In: Haenszel W, ed. Studies of disease among migrants and native populations in Great Britain, Norway, and the United States. (National Cancer Institute Monograph 19.) Bethesda, Maryland: National Institutes of Health, 1966:28799.

14 Wald NJ, Doll R. Epidemiology. In: Wynder EL, Hecht S, eds. Lung cancer. Geneva: International Union Against Cancer, 1976: ch 2. (UICC Technical Report Series, No 25.)

is Stepney R. Would a medium-nicotine, low-tar cigarette be less hazardous to health? $\mathrm{Br}$ Med J 1981; 283: $1292-6$.

${ }^{16}$ Sutton SR, Feyerabend C, Cole PV, Russell MAH. Adjustment of smokers to dilution of tobacco smoke by ventilated cigarette holders. Clin Pharmacol Therap 1978;24:395-405.

${ }^{17}$ Benowitz NL, Hall MS, Herning IR, Jacob P III, Jones TR, Osman A-L. Smokers of low yield cigarettes do not consume less nicotine. $N$ Engl J Med 1983;309: 139-42. 